\title{
e-Interview
}

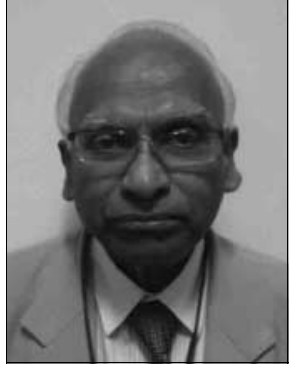

\section{Dr Rajan Thavasothy}

Dr Thavasothy is a Consultant Psychiatrist who advises the Care Quality Commission and the Court of Protection. He trained at Fulbourn Hospital, Cambridge, UK. His special interests include teaching.

If you were not a psychiatrist, what would you do?

As I have always enjoyed teaching, I would be an academic involved in undergraduate and postgraduate teaching. As clinical tutor and later as examiner and also as senior organiser of accreditations visits I was able to continue my interest in teaching.

What has been the greatest impact of your profession on you personally? Psychiatry enabled me to learn about myself, focusing mainly on weaknesses in my character. It continues to help in the development of my personality and has improved the quality of my life. Psychological insights into human behaviour has contributed towards a positive attitude towards others and society in general.

\section{Do you feel stigmatised by your profession?}

No. I am not affected by prejudices in society and hope that the quality of service we render as a profession will diminish prejudices.

What are your interests outside of work? Study and research in architecture, particularly in South and South-East Asia

- and travel to these areas.

Who was your most influential trainer, and why?

Dr David Clark at Fulbourn Hospital, Cambridge. Although I was not his trainee, I learnt by observing how he created a therapeutic environment in hospital, empowering patients with chronic mental illnesses and improving their quality of life.

What job gave you the most useful training experience?

As a senior registrar I served as a liaison psychiatrist to the transplant surgery unit in Cambridge. I was able to develop psychotherapeutic skills working with patients and their relatives. As this unit was internationally renowned and accepted patients from other parts of the world, I was able to obtain a transcultural perspective of organ donation. Conducting clinics at the Warwick University campus I gained experience in understanding adolescent crisis and providing appropriate psychological therapy. Depression, as a symptom, is a common problem but only a small percentage present with a depressive illness and other disorders.

Which publication has influenced you the most?

Sigmund Freud's Psychopathology of

Everyday Life kindled my interest in psychology and psychiatry. Later, Fish's Clinical Psychopathology edited by Max Hamilton introduced me to phenomenology.

How has the political environment influenced your work?

I have endeavoured to focus on patients' needs and be their advocate in influencing policy makers.

What part of your work gives you the most satisfaction?

Teaching undergraduates, postgraduates and other health professionals.

What do you least enjoy?

Protracted administrative meetings which do not end in a definitive course of action.

What is the most promising opportunity facing the profession?

Development of community care and the community treatment order facilitating better management and provision of care to patients who in the past needed compulsory admission to hospital.

\section{What is the greatest threat?}

Trust policies dictated by financial constraints limiting the provision of the best quality of care for patients.

What single change would substantially improve quality of care?

Multidisciplinary teams involved in assessments and care plans at times take critical decisions without adequate training. There is a need for better training and cleare definition of the roles of individual members of the multidisciplinary team taking into account their level and area of expertise.

What conflict of interest do you encounter most often?

Managers and clinicians who have different priorities.
What is the role of the psychiatrist in countries emerging from conflict? Psychiatrists could train health professionals and other professionals such as social workers and teachers in providing stress management programmes.

What is the most important advice you could offer a new trainee?

To develop the art of listening and establishing a relationship of trust. Trainees should be encouraged to have an enquiring mind and understand the clinical problem in the context of interacting psychological, social and physical factors. They should be able to crystalise these in a psychiatric formulation which should form the basis of a care plan.

What are the main ethical problems that psychiatrists will face in the future?

To judge whether a person's wish to end their life in the face of incurable, painful and protracted illness should be respected.

Do you think psychiatry is brainless or mindless?

Neither. Advances in neurosciences, including brain imaging and psychology, have contributed to the understanding of the functions of the brain and mind and their interactions.

What is the role of the psychiatrist in rebuilding healthcare systems?

(a) Focus on prevention, particularly with vulnerable groups such as school leavers, young offenders and young mothers;

(b) providing therapeutic programmes appropriate for different cultural groups; and (c) ensuring that patients who have difficulty in understanding English are still offered the whole range of therapies, particularly psychological therapy.

What single change to mental health legislation would you like to see? None.

What single area of psychiatric practice is most in need of development?

Mental health in adolescence, with particular focus on prevention.

What single area of psychiatric research should be given priority?

Neuroscientific research on Alzheimer's disease and neurobiological aspects of psychotic disorders.

How would you like to be remembered? As someone who enjoyed being a psychiatrist and a teacher.

Dominic Fannon

doi: 10.1192/pb.bp.111.035105 